\section{LATE LEFT ATRIAL THROMBOSIS OF AN AMPLATZER PATENT FORAMEN OVALE OCCLUDER MAY BE THE RESULT OF KOUNIS HYPERSENSITIVITY- ASSOCIATED SYNDROME \\ To the Editor:}

In the very interesting report by Klotz and colleagues ${ }^{1}$ published in this Journal, a patient with a patent foramen ovale that was successfully occluded with an Amplatzer occluder had a large thrombosis develop on the atrial disk of the device 33 months after the initial implantation. Although Klotz and colleagues ${ }^{1}$ did not refer to the etiology of thrombus formation, several such causes have been reported, including incorrect device placement, device size, device instability, anticoagulation, and antiplatelet therapy monitoring.

The Amplatzer closure device is made from nitinol, which is a nickeltitanium alloy. Nickel allergy is quite common, and in a recent report the overall prevalence was found to be $24.6 \%$. Titanium hypersensitivity, although low, has been seen in dental procedures and induces implant failure. ${ }^{2}$ The described patient received also aspirin and warfarin on several occasions, both of which are wellknown antigenic compounds. ${ }^{3}$ It is known that mast cells bring, on their surface, 500,000 to 1 million IgE molecules, and to degranulate they need 2000 of these molecules, which is a critical number, to make 1000

\footnotetext{
The Editor welcomes submissions for possible publication in the Letters to the Editor section that consist of commentary on an article published in the Journa or other relevant issues. Authors should: - Include no more than 500 words of text, three authors, and five references. - Type with double-spacing - See http://jtcs.ctsnetjournals.org/misc/ifora.shtm for detailed submission instructions. - Submit the letter electronically via jtcvs.editorialmanager.com. Letters commenting on an article published in the JTCVS will be considered if they are received within 6 weeks of the time the article was published. Authors of the article being commented on will be given an opportunity of offer a timely response ( 2 weeks) to the letter. Authors of letters will be notified that the letter has been received. Unpublished letters cannot be returned.
}

bridges with antigens. These bridges can be made by antigens of different specificities, as happens in patients with metal device implantation. It looks likely that the more antigens to which a patient with metal device implantation, is exposed the more easily and quickly the degranulation occurs. ${ }^{2}$

Nickel and titanium ions acting as antigens can activate platelets to release proinflammatory, prothrombotic, adhesive, and aggregatory mediators to induce thrombus formation. ${ }^{4}$ Platelet activation is taking place through stimulation of some known receptors in the platelet surface, such as receptors for adenosine diphosphate, for thromboxane, for thrombin, for serotonin, and for epinephrine, and through some lessknown receptors, such as receptors for platelet activating factor, for histamine, and for high-affinity and lowaffinity $\operatorname{IgE}$ receptors $\mathrm{FCeRI}$ and FCeRII. $^{2}$

Thrombus formation after left atrial appendage occulsion with an Amplatzer cardiac plug device can occur months after the procedure. Nickel allergy to intracardiac devices has caused systemic allergic reactions confirmed by patch tests to nitinol, which necessitated the removal of those devices. A device syndrome resembling Kounis syndrome and consisting of chest discomfort, exertional dyspnea, palpitations, asthenia, atrial fibrillation was reported in 8 of 9 patients in a series after Amplatzer implantation. Those patients had positive patch skin test reactions to nickel. $^{5}$

Although the rate of thrombosis complicating such devices might be low, we are still in the learning curve, and additional research is needed to prevent and treat such consequences. We recommend avoidance of metal device implantation in patients with known hypersensitivity or contraindication to any structurally related compound and to drugs these patients would need to take after implantation.
Nicholas G. Kounis, $M D, P h D, F A C C, F E S C^{a}$ George D. Soufras, $M D, P h D^{b}$ Andreas Mazarakis, $M D, P h D^{c}$

${ }^{a}$ Medical Sciences

Patras Highest Institute of Education and Technology

Patras, Greece

${ }^{b}$ Department of Cardiology

University of Patras Medical

Patras, Greece

${ }^{c}$ Department of Cardiology

Saint Andrews Patras State General

Hospital

Patras, Greece

\section{References}

1. Klotz S, Gebhard M, Sievers HH. Late left atrial thrombosis of an Amplatzer patent foramen ovale occluder. J Thorac Cardiovasc Surg. 2011;142: 1270-1.

2. Rui F, Bovenzi M, Prodi A, Fortina AB, Romano I, Peserico A, et al. Nickel, cobalt and chromate sensitization and occupation. Contact Dermatitis. 2010;62:225-31.

3. Bogart MA, Cheema A, Wooten JM, Bogart DB Warfarin allergy: an easy solution. Clin Cardiol. 2010;33:E31-2

4. Kounis NG, Mazarakis A, Tsigkas G, Giannopoulos S, Goudevenos J. Kounis syndrome: a new twist on an old disease. Future Cardiol. 2011; 7:805-24.

5. Rigatelli G, Cardaioli P, Giordan M, Aggio S, Chinaglia M, Braggion G, et al. Nickel allergy in interatrial shunt device-based closure patients. Congenit Heart Dis. 2007;2:416-20.

$$
\text { doi:10.1016/j.jtcvs.2012.03.071 }
$$

\section{Reply to the Editor:}

My coauthors and I read with great interest the Letter to the Editor by Kounis and colleagues regarding our case report of a left atrial thrombosis of an Amplatzer patent foramen ovale (PFO) occluder (St Jude Medical, St Paul, Minn) 33 months after implantation. ${ }^{1}$ Kounis and colleagues hypothesized that this thrombosis could the result of the Kounis hypersensitivity-associated syndrome. This syndrome describes, among others, an allergic reaction to intracardiac metal devices (such as PFO occluders and stents) containing nickel or other metals. ${ }^{2}$

We appreciate the input from Kounis and colleagues, which might give 
important hints to our case and future device applications. Regarding our case, we explicitly asked the patient for any known allergies at the time of the operation and repeated this query after the comment from Kounis and colleagues. The patient denied any allergies; however, a skin test for sensitivity to nickel or other metals was not performed. In addition, after initial interventional Amplatzer PFO occluder implantation, the patient was without any signs of discomfort, palpitations, dyspnea, headache, pericardial effusion, or conspicuously altered laboratory values, the main symptoms of Kounis hypersensitivity-associated syndrome, for almost 33 months. The symptom that precipitated readmission to the hospital was a stroke, which was most likely due to the thrombus formation on the atrial disk of the Amplatzer device. We cannot rule out, the possibility that the Kounis hypersensitivity-associated syndrome played some role in development of this thrombus formation; however, the histologic examination of the explanted device and thrombus did not reveal any inflammatory cells. In a multicenter-study of PFO closure device explants, the rate of explants was $0.28 \%{ }^{3}$ Most of these explants were due to persistent or unknown chest pain, and half of these patients had a known nickel allergy. In addition it is shown, that in patients with known nickel allergy the rate of chest discomfort and palpitations is significantly increased after PFO device closure. ${ }^{4}$ None of these signs were found in our patient.

We fully agree with Kounis and colleagues that a possible nickel allergy should be ruled out before elective implantation of intracardiac metal devices. Otherwise, the patient should be made aware of the possibility of device explantation when informed consent is obtained.

Stefan Klotz, MD Department of Cardiac and Thoracic Vascular Surgery
University Hospital Lübeck

Lübeck, Germany

\section{References}

1. Klotz S, Gebhard M, Sievers HH. Late left atrial thrombosis of an Amplatzer patent foramen ovale occluder. J Thorac Cardiovasc Surg. 2011;142:1270-1.

2. Kounis NG, Giannopoulos S, Tsigkas GG, Goudevenos J. Eosinophilic responses to stent implantation and the risk of Kounis hypersensitivity associated coronary syndrome. Int $J$ Cardiol. 2012;156:125-32.

3. Verma SK, Tobis JM. Explantation of patent foramen ovale closure devices: a multicenter survey. JACC Cardiovasc Interv. 2011;4:579-85.

4. Wertman B, Azarbal B, Riedl M, Tobis J. Adverse events associated with nickel allergy in patients undergoing percutaneous atrial septal defect or patent foramen ovale closure. JAm Coll Cardiol. 2006;47: 1226-7.

doi:10.1016/j.jtcvs.2012.03.070

\section{ENDOBRONCHIAL}

\section{ULTRASOUND-GUIDED}

MEDIASTINAL LYMPH NODE

NEEDLE ASPIRATION IN

NON-SMALL CELL LUNG

CANCER: FROM THEORY TO

PRACTICE

\section{To the Editor:}

We read with pleasure the article by Lee and colleagues. ${ }^{1}$ Endobronchial ultrasound-guided transbronchial needle aspiration (EBUS-TBNA) is a new diagnostic technique that provides a minimally invasive option for mediastinal staging in patients with lung cancer. This technique was described by Krasnik and colleagues ${ }^{2}$ in 2003 and rapidly gained the interest of the scientific community. Nonrandomized studies demonstrate that EBUS-TBNA affords excellent diagnostic performance with a sensitivity ranging from $70 \%$ to $99 \%$ and a negative predictive value up to $98 \%{ }^{3}$. Those excellent preliminary results convinced the American College of Chest Physicians to advocate EBUS-TBNA to stage the mediastinum only 4 years after the first description of the technique.

In 2006, we had the opportunity to use the first dedicated bronchoscope imported to Italy, and the potential of EBUS-TBNA was immediately obvious. The short learning curve, high diagnostic accuracy, minimal invasiveness, and possible surgical sparing encouraged us to use EBUSTBNA even outside of lung cancer staging. ${ }^{4}$

In a paradoxical way, the excellence of the preliminary results delayed the production of randomized studies, and to date only Annema and colleagues, ${ }^{5}$ pioneers in endobronchial ultrasound, published the randomized clinical trial, ASTER (Assessment of Surgical Staging Versus Endosonographic Ultrasound in Lung Cancer). In the aseptic world of scientific trials, the report by Lee and colleagues ${ }^{1}$ attracts our attention for its ability to focus interest on clinical practice. The brilliant results reported by the authors demonstrate the high diagnostic value of EBUSTBNA and the undoubtable skill of the operators. We do recommend rapid on-site evaluation of the specimen because it can decrease the rate of inadequate tests.

Reports with strong clinical characteristics, as well as randomized trials, are needed to validate EBUS-TBNA, especially for its potential capability of avoiding unnecessary surgery.

\section{Mario Nosotti, $M D$ \\ Matilde De Simone, $M D, P h D$ Ugo Cioffi, $M D, P h D$ \\ Department of Surgery \\ Fondazione IRCCS Ospedale Maggiore Policlinico \\ University of Milan \\ Milan, Italy}

\section{References}

1. Lee BE, Kletsman E, Rutledge JR, Korst RJ. Utility of endobronchial ultrasound-guided mediastinal lymph node biopsy in patients with non-small cell lung cancer. J Thorac Cardiovasc Surg. 2012; 143:585-90.

2. Krasnik M, Vilmann P, Larsen SS, Jacobsen GK Preliminary experience with a new method of endoscopic transbronchial real time ultrasound guided biopsy for diagnosis of mediastinal and hilar lesions. Thorax. 2003;58:1083-6.

3. Andrade RS, Groth SS, Rueth NM, D'Cunha J, Pambuccian SE, Maddaus MA. Evaluation of mediastinal lymph nodes with endobronchial ultrasound: the thoracic surgeon's perspective. J Thorac Cardiovasc Surg. 2010;139:578-82.

4. Nosotti M, Tosi D, Palleschi A, Ferrero S, Rosso L. Transbronchial needle aspiration under direct endobronchial ultrasound guidance of PET-positive 